\title{
Evaluation of Microbial Communities Colonizing Stone Ballasts at Diesel Depots
}

\author{
MPHEKGO P. MAILA and THOMAS E. CLOETE
}

\section{Introduction}

Diesel oil is a complex mixture of normal, branched and cyclic alkanes, and aromatic compounds obtained from the middle-distillate, gas-oil fraction during petroleum separation (WHO, 1996). These hydrocarbons have the potential to cause considerable damage not only to the soil but also to water intakes or ground-water reservoirs due to the mobility of some of the hydrocarbon compounds. At diesel depots, the contamination of stone ballasts which are used as support structures for railroads also pose a significant risk to both the ground water resources and to humans as they can be exposed to both volatile and non-volatile hydrocarbons. The heterotrophic bacteria, or more specifically the hydrocarbon degrading bacteria, can play an important role in mitigating these environmental problems as they can limit the mobility of petroleum contaminants by degrading the pollutants to avoid, for example, groundwater contamination. According to Atlas (1981) and Leahy and Colwell (1990), the number of hydrocarbon degrading bacteria and their relative abundance in the bacterial communities increases significantly in the presence of readily available hydrocarbons. Hydrocarbon utilizing bacteria are ubiquitously distributed in natural environments and their proportions in the heterotrophic bacterial soil communities ranges from 0.13 to $50 \%$ (Jones et al., 1970; Pinholt et al., 1979).

Most knowledge into the effect of hydrocarbons on microbial diversity has been generated using soil as a medium (Urzí et al., 1999; Bundy et al., 2002). The information about microbial diversity of hydrocarbons polluted rocky surfaces is not well documented. There is a need to study heterotrophic diversity on rocky surfaces as this information can be useful in the cleanup of hydrocarbon contaminated stone ballasts. Stone surfaces tend to accumulate inorganic and organic substances from the surrounding environment, most of which can serve as nutrients for many microorganisms (Urzí et al., 1999).

At diesel depots, the ballasts are continuously contaminated with hydrocarbons from the parked locomotives and general maintenance work. These rocky surfaces used on railroads are usually of the quartzite, fine-grained basic plutonic rock and other rock types. The loading rate of the hydrocarbons on the ballast varies depending on the traffic load at the depots and therefore the degree of contamination of the ballasts reflects the intensity of the activities at the depot. The concentration or thickness of hydrocarbons on the ballast that encourages the attachment or colonization of the heterotrophs and the hydrocarbon degrading bacteria will vary from site to site. The information about heterotrophic diversity at contaminated rocky surfaces such as the hydrocarbon-contaminated ballasts can be useful for bioremediation purposes.

In this study we investigated the heterotrophic diversity of polluted stone ballast at different diesel depots using culture dependant methods, community level physiological profiles and respiration. The aim of the experiment was to test the hypothesis that hydrocarbons deposition on the stone ballast at different diesel depots selects for similar microbial communities dominated by hydrocarbon degrading bacteria.

\section{Materials and methods}

\subsection{Stone ballast}

The contaminated stone ballasts were collected in sterile bags from Koedoespoort (Kc), Sentrarand (SRc), 
Pyramid ( $\mathrm{Pc}$ ) and Springs (SPc) diesel depots, in Gauteng province, South Africa. The uncontaminated stone ballasts were collected from the Pyramid $(\mathrm{Pu})$ and Sentrarand (SRu) diesel depots. The ballasts were ground using Keegor jaw crusher (Dickie and Stockler Pty, SA) under sterile conditions to reduce the size of the stones before analysis. The diameter of the ground stone ballasts used in the experiment averaged $1 \mathrm{~cm}$. The ballasts had size distribution when collected and the proportion of exterior contaminated stones after grinding was much higher than the interior uncontaminated stones. The exterior contaminated stones averaged $1 \mathrm{~cm}$ in diameter while the interior uncontaminated stones averaged less than $0.5 \mathrm{~cm}$. The ground ballasts averaging $1 \mathrm{~cm}$ in diameter were used in the experiment. The stone used as ballasts at diesel depots were prepared using fine-grained basic plutonic rocks. Samples were kept at $4^{\circ} \mathrm{C}$ until analysis. All analyses were done within 24 hours.

\subsection{Enumeration of microorganisms}

$250 \mathrm{ml}$ of sterile $0.2 \%$ tetrasodium pyrophosphate was added to $500 \mathrm{ml}$ Erlemeyer flask containing $25 \mathrm{~g}$ of the ground stone ballasts from each diesel depots. The flasks were placed on a shaker (140 rpm) for $45 \mathrm{~min}$. The mixtures in the flasks were allowed to settle for 5 min after mixing. Serial dilutions (with sterile saline solution) were done using the samples before inoculating both the agar plates and the Biolog GN plates. The total culturable heterotrophs (TCHs) were enumerated by spread plate technique using nutrient agar (Biolab Diagnostics Pty Ltd, SA). The hydrocarbon-degrading bacteria were isolated using the mineral salt medium in which the filtersterilised diesel 3\% $(v / v)$ was used as the sole carbon and energy source. The composition of the mineral salt medium is shown in Table 1. Bacteriological agar $\left(15 \mathrm{~g} / \mathrm{L}\right.$, Biolab Diagnostics) was autoclaved $\left(121^{\circ} \mathrm{C}, 15 \mathrm{~min}\right)$ before adding the sterile solutions (Table 1). Cycloheximide $(200 \mathrm{mg} / \mathrm{L})$ was added in both media to inhibit fungal growth. Both plates were incubated at $28^{\circ} \mathrm{C}$ and counted after $24 \mathrm{~h}$ and $7 \mathrm{~d}$ respectively. Plates were incubated at $28^{\circ} \mathrm{C}$ as this was the average temperature (in the region) during the sampling period and also because most heterotrophic bacteria are able to grow optimally at this temperature.

Table 1. Composition of mineral salt medium

\begin{tabular}{|c|c|c|c|}
\hline $\begin{array}{c}\begin{array}{c}\text { Trace mineral } \\
\text { solutions }\end{array} \\
\end{array}$ & Compounds & $\mathrm{g} \mathrm{L}^{-1}$ stock & $\begin{array}{c}\text { Concentration in } \\
\text { media } \mathrm{g} \mathrm{L}^{-1}\end{array}$ \\
\hline \multirow[t]{2}{*}{ A } & $\mathrm{Na}_{2} \mathrm{HPO}_{4}$ & 141.96 & 10 \\
\hline & $\mathrm{KH}_{2} \mathrm{PO}_{4}$ & 136.09 & 10 \\
\hline B & $\left(\mathrm{NH}_{4}\right)_{2} \mathrm{SO}_{4}$ & 100 & 2.5 \\
\hline $\mathrm{C}$ & $\mathrm{MgSO}_{4}$ & 19.7 & 0.4 \\
\hline $\mathrm{D}$ & $\mathrm{CaCl}_{2} \cdot 2 \mathrm{H}_{2} \mathrm{O}$ & 1.15 & 0.05 \\
\hline \multirow[t]{7}{*}{$\mathrm{E}$} & EDTA & 0.64 & 0.0086 \\
\hline & $\mathrm{FeSO}_{4} \cdot 7 \mathrm{H}_{2} \mathrm{O}$ & 0.55 & 0.01 \\
\hline & $\mathrm{ZnSO}_{4} \cdot 7 \mathrm{H}_{2} \mathrm{O}$ & 0.23 & 0.004 \\
\hline & $\mathrm{MnSO}_{4} \cdot \mathrm{H}_{2} \mathrm{O}$ & 0.34 & 0.01 \\
\hline & $\mathrm{CuSO}_{4} .5 \mathrm{H}_{2} \mathrm{O}$ & 0.075 & 0.0015 \\
\hline & $\mathrm{Co}\left(\mathrm{NO}_{3}\right)_{2} .6 \mathrm{H}_{2} \mathrm{O}$ & 0.047 & 0.0008 \\
\hline & $\left(\mathrm{NH}_{4}\right)_{6} \mathrm{Mo}_{7} \mathrm{O}_{24} .4 \mathrm{H}_{2} \mathrm{O}$ & 0.025 & 0.0001 \\
\hline
\end{tabular}

Bacterial counts were done in triplicate (three true replicates stones were ground to prepare the dilution series). ANOVA (Analysis of Variance) was used to determine the difference between the TCHs and hydrocarbon degrading bacteria.

\subsection{Carbon source utilisation pattern determination}

Sample dilutions were done as described above. Dilutions yielding similar bacterial counts (TCHs) in the ballast samples (from SRc, Kc and SPc) were used for carbon utilization pattern analysis. $100 \mu l$ of each sample was added to each well (Biolog GN microplates). The optical density $\left(\mathrm{OD}_{600}\right)$ of the plates was measured in triplicate (three Biolog plate per ballast sample) using Bio-TekElx800 microreader (Bio-Tek Instruments Inc) at time 0 and after 24, 48 , and $72 \mathrm{~h}$ of incubation at $28^{\circ} \mathrm{C}$. Statistical analyses (Principle Component Analysis and Cluster Analysis) were 
done using STATISTICA for Windows release 5.1.

\subsection{Respiration rate determination}

The biological activity of the contaminated ballasts was evaluated by monitoring carbon dioxide production using a Micro-Oxymax Respirometer (Columbus Instruments). $20 \mathrm{~g}$ of the grinded contaminated stone ballasts were added to a $250 \mathrm{ml}$ bottle containing the sterile $150 \mathrm{ml}$ nutrients (mineral salt medium as shown in Table 1) with no carbon and energy source. The nutrients were added to the contaminated ballast to stimulate bioremediation. The treatments in which sterile deionised water was added to the ballast, instead of nutrients, served as controls. The $\mathrm{CO}_{2}$ production was measured over $46 \mathrm{~h}$. The composition of the different solutions used to prepare the nutrient solution is shown in Table 1.

\subsection{Chemical analysis}

The contaminated stone ballasts were ground as described in Section 2.1 and Total Petroleum Hydrocarbons (TPH) was analysed using the EPA 418.1 method (US Environmental Protection Agency, 1983). $25 \mathrm{~g}$ of the ground ballasts were used for the analysis. After extraction of the ballasts with 1,1,2-trichloro-trifluoro-ethane, the hydrocarbon content was quantified by infrared spectroscopy. The analyses were done in triplicate.

\section{Results}

\subsection{Microbiological and chemical analysis}

The number of bacteria (both total culturable heterotrophs and hydrocarbon-degrading bacteria) on the polluted ballast was high in diesel depots samples with high concentration of hydrocarbons (Fig. 1). However, there was no

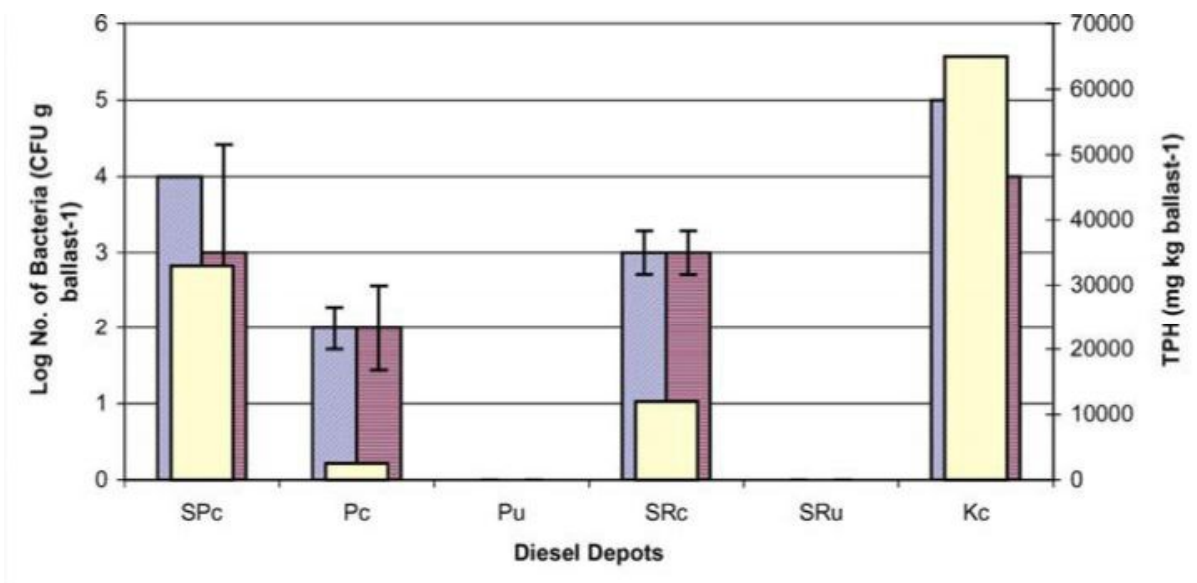

口Total Culturable Heterotrophs (TCHs) 口Hydrocarbon-Degrading Bacteria 口Total Petroleum Hydrocarbons (TPH)

Figure 1. The number of culturable heterotrophic bacteria and the concentration of hydrocarbons at different diesel depots. Values are the means of three replicates ( $\mathrm{SD} \pm 1.4$ or less). SPc- Springs contaminated ballast, Pc- Pyramid contaminated ballast, Pu- Pyramid uncontaminated ballast, SRc- Sentrarand contaminated ballast, SRu- Sentrarand uncontaminated ballast, Kc- Koedoespoort contaminated ballast.

significant difference $(p<0.05)$ between the total culturable heterotrophs (TCHs) and the hydrocarbondegrading bacteria in the diesel depots samples. The number of total culturable heterotrophs on the polluted stone ballast was highest in the Koedoespoort ballast $(\mathrm{Kc})$, followed by the Spring ballast (SPc), Sentrarand (SRc) and the Pyramid (Pc) ballast. Similar bacterial counts for TCH and hydrocarbon-degrading bacteria were 
counted at both Pc and SRc. The number of hydrocarbon degrading bacteria and the TCHs in the uncontaminated Pyramid $(\mathrm{Pu})$ and uncontaminated Sentrarand ballast (SRu) were statistically not significant. The hydrocarbon concentration at the diesel depots was highest at Koedoespoort depots (Kc) followed by SPc, SRc and the Pyramid diesel depots. There was a significant difference $(p<0.05)$ between the hydrocarbon concentrations at the different diesel depots.

\subsection{Respiration rate determination}

Addition of nutrients stimulated the biological activity of the samples and possibly the removal of hydrocarbons. However, this was only evident in the LSPc and LKc. The biological activity as measured by $\mathrm{CO}_{2}$ production was very low in the LSRc, LPu, LSRu, LPc and the control (Fig. 2). The rate of $\mathrm{CO}_{2}$ production in the diesel depots samples was higher in the nutrient amended samples in which high numbers $\left(\geq 10^{4} \mathrm{CFU} / \mathrm{g}\right.$ ballast) of TCHs were present. No significant production of $\mathrm{CO}_{2}$ was evident in the samples with low or no culturable heterotrophs (LSRc, LPc, LPu, LSRu and the controls).

\subsection{Carbon source utilization profiles}

Principle Component Analysis (PCA) was performed to characterize the correlation amongst samples, using the absorbance values of all 96-response wells. Two principal factors were isolated from the individual SRc, Kc, SPc (Fig. 3) patterns, which explained $63 \%$ of the variation. For the three samples, factor one was related to the absorbance values for the wells, while factor 2 was related to the incubation time.

The Kc and SRc samples (at $24 \mathrm{~h}$ and $48 \mathrm{~h}$ incubation periods) had a similar pattern of carbon source utilization based on PCA (Fig. 3). However, the similarities in carbon source utilization patterns appeared to diminish with increasing incubation time (after 48 h, Fig. 3). At 72 h, Kc and SRc were less similar than at the shorter incubation times, and SPc is much less similar to Kc and SRc. The trend over time is greater divergence of carbon source utilisation patterns, more so for SPc than for Kc and SRc.

The relationship between the substrate utilization patterns was further analysed using hierarchial clustering. In a dendrogram (Fig. 4), the results of cluster analysis confirmed the degree of similarities between the samples (Fig. 4).

Both the dendrogram and the PCA illustrate that the substrate utilization pattern of microbial communities at different diesel depots were different.

\section{Discussions and conclusion}

The microbiological analysis indicated that the number of culturable bacteria on the polluted ballasts was high in diesel depot samples with high concentration of hydrocarbons. This can be attributed to the availability of the readily biodegradable hydrocarbons on the ballast, which can encourage the colonisation of the heterotrophs on the ballasts. According to Atlas (1981) and Leahy and Colwell (1990), the number of hydrocarbon degrading bacteria and their relative abundance in the bacterial communities increases significantly in the presence of readily biodegradable hydrocarbons. The analysis of variance indicated that the number of total culturable heterotrophs (TCHs) were not significantly different from the number of hydrocarbon-degrading bacteria. The results suggest that the number of hydrocarbon degrading bacteria forms the majority of the total culturable heterotrophic bacteria in the hydrocarbon-contaminated stone ballasts. The number of hydrocarbon degrading bacteria and the TCHs in the uncontaminated Pyramid and uncontaminated Sentrarand ballasts were statistically not significant. This can be attributed to the lack of the readily biodegradable organic compounds on the diesel ballasts.

The production of $\mathrm{CO}_{2}$ by microorganisms in the diesel depots samples was higher in only two of the nutrient amended samples compared to the controls. This 'divergent' $\mathrm{CO}_{2}$ data can be attributed to the probable heterogeneousness of the ballast samples in terms of the real amount of hydrocarbon 'added' to the bottles. The results also suggest that the activity of LSRc and LPc was very low and the community cannot be marked as 'active'. In addition, the high $\mathrm{CO}_{2}$ production in LKc and LSPc appears to reflect the higher 


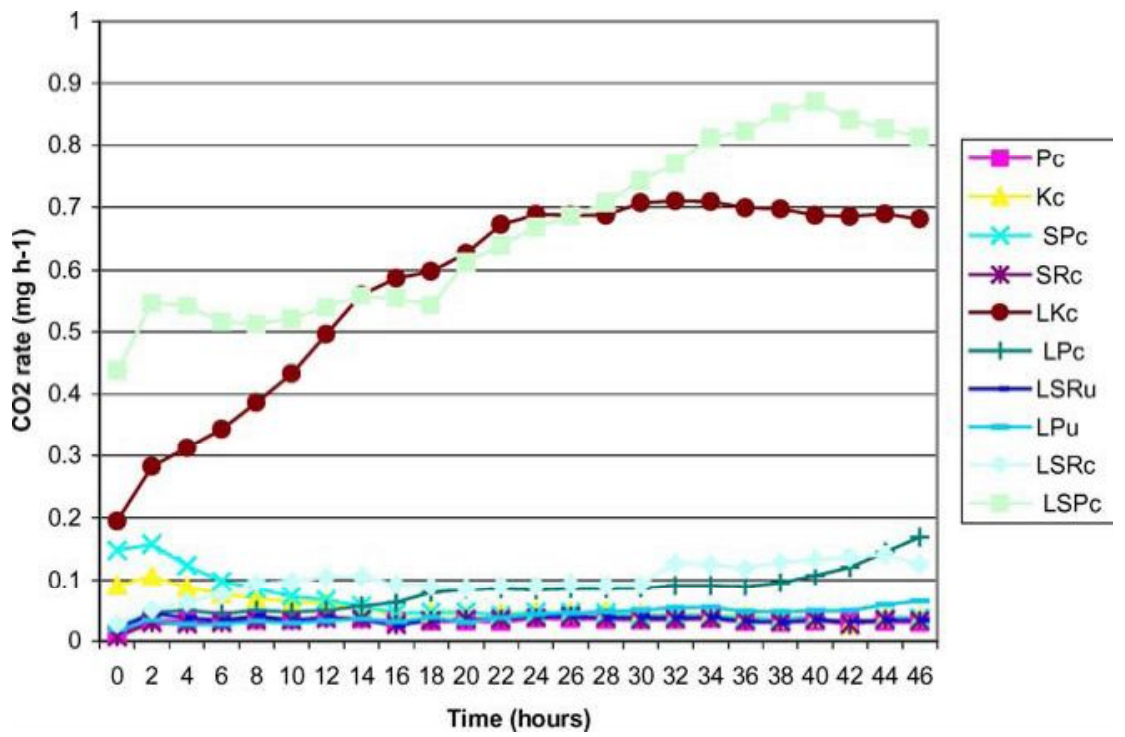

Figure 2. $\mathrm{CO}_{2}$ production by microorganisms in different diesel depots samples. Pc: Pyramid contaminated stone ballast, Kc: Koedoespoort contaminated ballast, SPc: Springs contaminated ballast, SRc: Sentrarand contaminated ballast, LKc: nutrient amended Koedoespoort contaminated ballast, LPc: nutrient amended Pyramid contaminated ballast, LSRu: nutrient amended Sentrarand uncontaminated ballast, LPu: nutrient amended Pyramid uncontaminated ballast, LSRc: nutrient amended Sentrarand contaminated ballast, LSPc: nutrient amended Springs contaminated ballast.

carbon source (hydrocarbon) content and larger bacterial inoculum at the beginning of the test. The addition of nutrients (mainly nitrogen and phosphorus) has been reported to stimulate the biological activity in hydrocarbon contaminated soil environments (Churchill et al., 1995; Braddock et al., 1997; Seklemova, 2001).

The number of carbon source (of Biolog plates) used by the SRc sample was four times the number

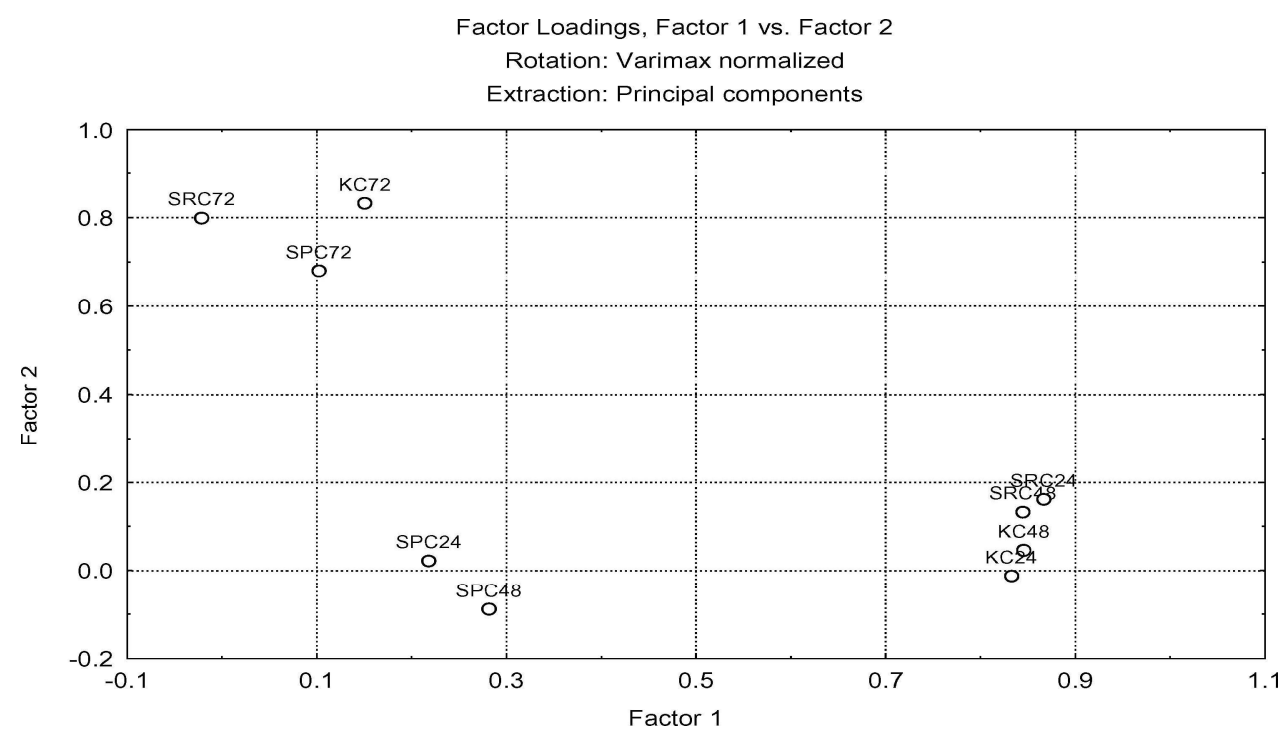

Figure 3. The relationship between microbial communities of different diesel depots as depicted by principal component analysis (readings for different incubation times are shown). 


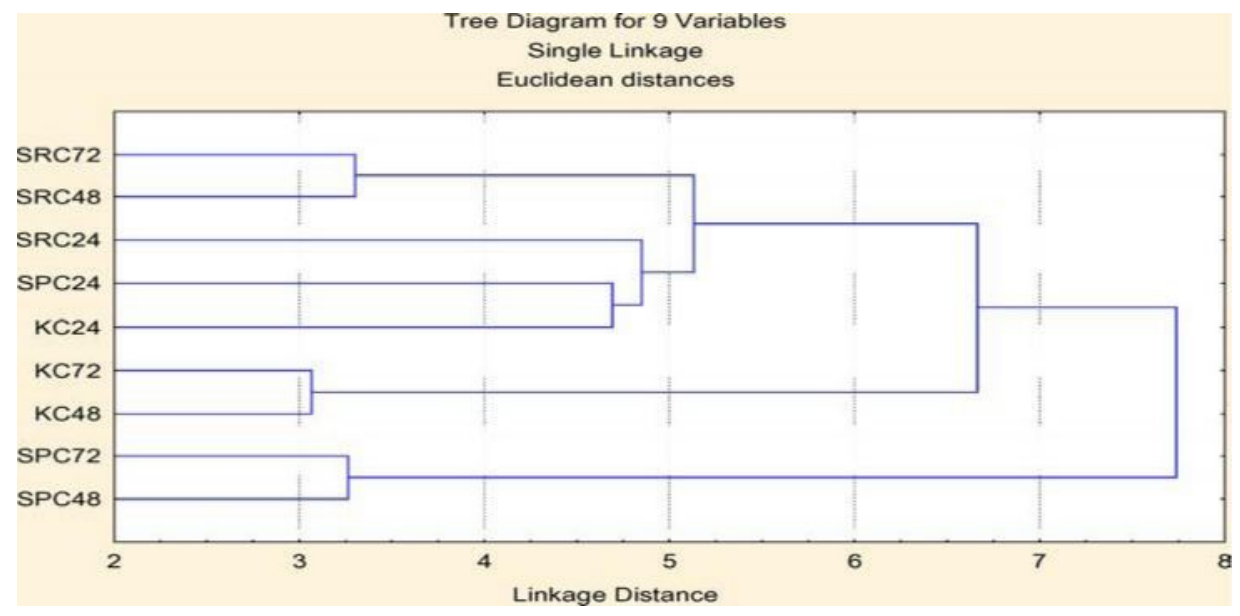

Figure 4. The relationship between microbial communities of the different polluted stone ballasts resulting from cluster analysis (readings for different incubation times are also shown).

of substrates used by the Springs contaminated stone ballast (SPc) after 24 hours of incubation. This suggests higher degradation capacity in the SRc sample compared to the SPc sample as both samples were adjusted to have similar cell density for Biolog plate inoculation. According to Wünsche et al. (1995), at lower incubation periods, Biolog patterns reflect the metabolic activities of the quantitatively dominating components of the microbial communities.

Influence of incubation time on the development of the substrate utilization pattern of the samples was similar to that reported elsewhere (Garland and Mills, 1991; Winding, 1994; Haack et al., 1995; Kersters et al., 1997). The Biolog substrate oxidation response and average well color developments often exhibit a lag phase, an exponential phase and a stationary phase. This non-linearity implies that the substrates to be most significant in discriminating microbial communities may change over the course of the experiment. A cursory glance at the results suggests that this is responsible for the dendrogram pattern, as the relationship between the samples appears to vary with incubation time.

Microbial colonization of rocky surfaces by heterotrophs is made possible by (among other things) the availability of the selective substrates that can be used to sustain the heterotrophic community. In diesel depots in which similar human activities results in the contamination of stone ballasts by hydrocarbons, patterns of substrates utilization of the heterotrophs was expected to be similar. This was, however, not realised in this study, as the substrate utilisation patterns of the different samples were different. Both the principle component analysis (PCA) and cluster analysis indicated the degree of dissimilarity between the different diesel depots samples. Using cluster analysis, SRc and Kc were closely related compared to the SPc. However, using the PCA, the three samples (SRc, Kc and SPc) after 72 hours of incubation were lumped together, suggesting the extent of similarity in the pattern of substrate utilisation.

Microbial diversity of polluted surfaces needs to be studied further to investigate the concentration or the thickness of the hydrocarbons layer on the rock surfaces that encourages the attachment or colonization of the TCHs and the hydrocarbon-degrading bacteria. It is also not clear how the heterotrophs acquire the micronutrients from the surrounding environment. Knowledge of microbial diversity of contaminated rocky surfaces is essential as it can be applied in bioremediation of contaminated rocky surfaces as in contaminated diesel depots and contaminated rocky surfaces caused by oil spills. 


\section{Acknowledgments}

We thank the Risk and Environmental managers at (Spoornet) Diesel depots for allowing and helping us to collect the samples. Special thanks also goes to Dr. P. Wade for assisting us with the Statistical analysis. The National Research Foundation and the CSIR supported this work.

\section{References}

Atlas, R.M.: 1981, Microbiol. Rev. 45, 180.

Braddock, J., Ruth, M., Catteral, P., Walworth, J. and Mcarthy, K.: 1997, Environ. Sci. Technol. 31, 2078.

Bundy, J.G., Paton, G.I. and Campell, C.D.: 2002,J. Appl. Microbiol. 92, 276.

Churchill, S.A., Griffin, R.A., Jones, L.P. and Churchill, P.F.: 1995, J. Environ. Qual. 24, 19

Garland, J.L. and Mills, A.L.: 1991,Appl. Environ. Microbiol. 57(8), 2351.

Haack, S.K., Garchow, H., Klug, M.J. and Forney L.J.: 1995, Appl. Environ. Microbiol. 61, 1458.

Jones, J.G., Knight, M. and Byron, J.A.: 1970, Nature (Lond.) 227, 1166.

Kersters, I., Van Vooren, L., Verschuere, L., Vautern, L., Wouters, A., Mergaert, J., Swings, J. and Verstraete, W.: 1997, Syst. Appl. Microbiol. 20, 439 .

Leahy, J.G. and Colwell, R.R.: 1990, Microbiol. Rev. 54, 305.

Pinholt, Y., Struwe, S. and Kjoller, A.: 1979, Holarctic Ecol. 2, 195.

Seklemova, E., Pavlova, A. and Kovacheva, K.: 2001, Biodegradation 12, 311.

Urzí, C., Garcia-Valles, M., Vendrell, M. and Pernice, A.: 1999, Geomicrobiol. J. 16, 39.

US Environmental Protection Agency.: 1983, EPA 600/4-79-020, Washington DC.

WHO.: 1996, International Program on Chemical Safety, World Health Organization, Geneva.

Winding, A.: 1994,in K. Ritz, J. Dighton, K.E. Giller, (eds.),Beyond the Biomass: Compositional and Functional Analysis of Soil Microbial Communities, Chichester, Wiley, pp. 85.

Wünsche, L., Bruggemann, L. and Babel, W.: 1995, FEMS Microbiol. Ecol. 17, 295. 